\title{
ORGANIZACIONES CIUDADANAS COMO MECANISMOS DE CONTROL «MEDICIÓN E IDENTIFICACIÓN DE LAS QUEJAS PRESENTADAS POR LOS CONSUMIDORES, REFERENTE A LA PRESTACIÓN DE LOS SERVICIOS PÚBLICOS EN SECTORES DE LA ECONOMIA».
}

\author{
Mirian Solano Quintero', \\ Henry Cañón Salazar², \\ Edgar Eduardo Moreno ${ }^{3}$, \\ Néstor Julio Castro ${ }^{4}$ \\ Oscar Luis Martínez ${ }^{5}$
}

\section{Resumen}

¿Cual es la importancia que tienen las organizaciones ciudadanas como mecanismos de control eficientes de las organizaciones?, ¿más específicamente las ligas de consumidores? En este articulo encontrará el lector una descripción de forma clara la incidencia social de este tipo de organizaciones y la importancia de una gestión clara y procedimentada para su eficiencia y buen servicio al ciudadano, y para dar sustento a la pregunta planteada, se construye un marco teórico apoyado en conceptos de otros autores, que señalan los aspectos más importantes que se tienen de las organizaciones ciudadanas como mecanismos de control y la ayuda que le prestan a las organizaciones y comunidades y los beneficios que genera esto para las empresas. Para abordar el tema directamente en su contexto, se optó por el método de realizar un trabajo de campo en diversas entidades de ligas de consumidores de la economía, agrupadas a través de la Confederación Colombiana de Consumidores (CCC), de tal forma que se obtenga información primaria que permita luego de un análisis serio, establecer conclusiones que respondan a la inquietud planteada.

Palabras clave: Organizaciones ciudadanas, mecanismos de control, ligas de consumidores.

\footnotetext{
Administradora de Empresas de la Universidad Tecnológica del Choco, Especialista en Gerencia Integral de la Calidad de la Sergio Arboleda, Candidata a Maestrante en Administración de la Organizaciones, Docente Universidad Nacional Abierta y a Distancia - UNAD, Mirian.solano@unad.edu.co.

${ }^{2}$ Administrador de Empresas de la Universidad Jorge Tadeo Lozano, Especialista en Gerencia de Proyectos, Maestría en Direccionamiento Estratégico de la Universidad de León de España.

${ }^{3}$ Administrador de Empresas, Candidato a Maestrante en Administración de la Organizaciones, Docente Universidad Nacional Abierta y a Distancia - UNAD

${ }^{4}$ Administrador de Empresas, Esp. en Docencia Universitaria, Esp. en Gerencia de Proyectos Educativos, candidato a Mg. en Administración de Organiza-

ciones.nestor.castro@unad.edu.co.

${ }_{5}^{5}$ Administrador de Empresas, Candidato a Maestrante en Administración de la Organizaciones - UNAD
} 


\section{CITIZEN ORGANIZATIONS AND CONTROL MECHANISMS “MEASUREMENT AND IDENTIFICATION OF CONSUMER COMPLAINTS CONCERNING THE PROVISION OF PUBLIC SERVICES IN SECTORS OF THE ECONOMY.”}

\section{Abstract}

Throughout this article, it shows the importance that citizen organizations have as mechanisms of control of organizations, specifically the consumer leagues. In its introduction it clearly describes what the reader will find inside the writing, and to give support to the raised question, it constructs a theoretical framework supported by concepts of other authors, who point out the most important aspects of citizen organizations as control mechanisms and the help that they lend to organizations and communities, and the benefits they generate for businesses. To address the issue directly in context, the method of doing fieldwork in various institutions "of leagues" of consumer economics is chosen, grouped by the Colombian Confederation of Consumers (CCC), in such a way as to obtain primary information that permits after a serious analysis, conclusions that address the concerns raised.

Keywords: Civic organizations, control mechanisms, consumer leagues.

\section{Introducción}

Los ciudadanos son los usuarios directos de los bienes y servicios que demandan las diversas entidades y organizaciones en los diferentes sector, tanto desde lo público como en lo privado. Como sabemos hay productos y servicios que son de primera necesidad, básicos y fundamentales para el ser humano, en este sentido son de carácter obligatorio para el ser humano su uso y beneficio como los servicios públicos. En muchos casos, la prestación de este tipo de servicios, no se presta de la mejor manera presentándose falencias e inconsistencias que obligan a los ciudadanos a reaccionar frente a los abusos cuando han sido víctimas.

Las ligas de consumidores, desde su naturaleza normativa, tienen como objetivo «garantizar la protección, la información, la educación, la representación y el respeto de los derechos de los consumidores de bienes y servicios,...", Decreto 1441 de 1982. En este marco, con esta investigación, se quiere tener un aproximado sobre qué tan eficientes, como mecanismos de control son las ligas de consumidores en la defensa de los derechos de los usuarios y consumidores en los diferentes sectores económicos, mediante la identificación y medición de las quejas presentadas por los consumidores, referente a la prestación de los servicios públicos en sectores de la economía.

Para realizar esta investigación se aplicó una encuesta a 84 trabajadores expertos de la Confederación de Consumidores de Colombia - CCC, sede Bogotá. Se realizó una investigación es de corte cuantitativo, descriptivo, no experimental, con diseño longitudinal cuyos resultados muestran en gran medida los impactos de estas ligas en la calidad de la prestación de los servicios en los sectores económicos en las cuales se cimenta y se justifica su existencia.

\section{Antecedentes}

Hablar de sociedad civil, es complejo por la cantidad de definiciones que se encuentran en el mundo académico. Además a lo largo del tiempo, esta respuesta ha ido variando. El término fue acuñado en el mundo clásico, cuando se le 
equiparaba con el Estado; pero en su versión moderna, es necesario recurrir al iluminismo escocés para hallar sus orígenes. Así entonces se debe partir del Adam Ferguson quien es su obra La Historia de la Sociedad Civil (1767) señala que la sociedad civil es el ámbito de la civilización, en el cual, gracias a las ventajas de la división del trabajo, se obtienen beneficios de la modernidad, tales como crecientes estándares de calidad de vida. Sin embargo, Ferguson también considera que la sociedad civil introduce el riesgo de disgregación social al dar lugar a los diversos intereses de los individuos. Posteriormente en el S. XIX, Hegel, señalará que la sociedad civil es en dominio paralelo al Estado, pero separado de este. En él asociacionismo de los individuos se basa en sus preferencias e intereses particulares.

Estas dos etapas muestran cómo el pensamiento político y social refleja los cambios tecnológico, económico, organizaciones y políticos experimentados por el mundo: revolución industrial, propiedad privada, libre-mercado, surgimiento de la burguesía e incipientes demandas de libertad.

Más recientemente en el Siglo XX Antonio Gramsci, señala que la sociedad civil es una esfera de resistencia contra la tiranía, un espacio de discusión política independiente. En esta área, las clases dominadas pueden contestar al discurso de los dominantes y organizarse para generar un cambio en la estructura social.

En todas estas versiones la sociedad civil aparece como un espacio de organización voluntaria, independiente del Estado, incluso contrapuesta a éste, para perseguir los fines de los individuos.

A partir de la década de los años 90 surgen otros tres re-significados para la sociedad civil. Por un lado, sería una alternativa en la cual el Estado podría delegar la ejecución de ciertas funciones que le eran propias en tanto Estado de Bienes- tar para que fueran desarrolladas más eficazmente (neoliberalismo, privatizaciones, Estado mínimo). Por otro lado, desde la perspectiva de Tocqueville se interpreta a la sociedad civil como una "escuela de republicanismo» que contribuye a la calidad de la cultura política y las instituciones democráticas, en este escenario se puede incluir los desarrollos relacionados con el capital social por ejemplo. También se interpreta la sociedad civil en el contexto que configuran las nuevas tecnologías de la información, es decir, como un espacio en el que los ciudadanos se conectan, se empoderan y pueden contestar más eficazmente al Estado.

Ya en la década de los años 90, y posteriormente, cuando se habla de sociedad civil, se hace referencia generalmente a las ONG, más que en uniones, organizaciones comunales o el tradicional sector sin fines de lucro. Sin embargo la sociedad civil es algo mucho más amplio que comprende todo tipo de organizaciones y asociaciones, sindicatos, particos, asociaciones profesionales, cámaras de comercio, clubes, organizaciones vecinales y comunidades de base, todos con diferentes intereses, los cuales pueden ser sectorial, religiosos, culturales, políticos, de género, etc.

\section{Fundamentos teóricos}

A continuación se referencian los fundamentos teóricos de cultura ciudadana ${ }^{1}$

\section{Ley, moral y cultura}

Existen reglas informales que son un complemento inevitable de las reglas formales (legales). Cuando en una sociedad hay armonía entre unas y otras, los costos de celebrar y cumplir acuerdos se reducen; cuando se contradicen o la evolución de unas no se adecúa a la de las

1 Este enfoque teórico fue tomado literalmente de la guía práctica de Cultura Ciudadana elaborada por el profesor Antanas Mockus y un equipo de la Universidad Nacional, integrado por Paul Bromberg, Rocío Londoño, Efraín Sánchez, Claudia Peñaranda y Carolina Castro, está elaborando mediante un convenio con el PNUD. 
otras, los costos de celebrar y cumplir acuerdos se incrementan (Douglass North recibió en 1993 el premio Nóbel de Economía por haber desarrollado estas ideas y haberlas aplicado con éxito para explicar por qué las sociedades se desarrollan a ritmos tan distintos).

Las reglas morales expresan básicamente principios interiorizados que cada persona aplica «desde adentro» y que le provocan culpa en caso de violarlos y satisfacción moral en caso de respetarlos. Las reglas morales se manifiestan a través de un sentido del deber y de la capacidad de actuar obedeciendo a ese sentido (algo muy emparentado con la propio-motivación o motivación intrínseca y muy distinto de la hetero-motivación o motivación extrínseca). Las pedagogías de la concientización (tan propias de Latinoamérica y en general del Tercer Mundo) intentan influir sobre estas reglas, buscando generar más solidaridad y cooperación, especialmente entre desconocidos que comparten una misma condición social.

La regulación cultural se expresa de manera más compleja. En primer lugar, las normas sociales cuya desobediencia lleva a la posibilidad de sanciones sociales (desde ver que alguien frunce el ceño en señal de desaprobación o censura, hasta ser excluido de un grupo) que por lo general inducen sentimientos de vergüenza. En segundo lugar, la cultura regula a través de una delimitación y una jerarquización de los significados que contribuyen mucho al reconocimiento, el reconocimiento se traduce en confianza. La cultura también involucra creencias, valores e ideales que (de una manera menos afín a la de las normas legales) también orientan el comportamiento de las personas. Lo clave es que a través de diversos mecanismos, en cada medio socio-cultural se logra una delimitación cultural de comportamientos culturalmente bien considerados, comportamientos neutros y comportamientos considerados (culturalmente) inaceptables.
Cabe entonces retomar el tema de consistencia regulatoria: lo que nos ordena la ley puede ser consistente o no con lo que nos ordena la conciencia o con lo grupalmente aceptado como válido. Además una misma persona puede pertenecer a grupos distintos que no comparten una cierta norma (por ejemplo un grupo aprueba fumar mientras otro rechaza fumar). Algo de tensión entre ley, moral y cultura puede ser útil para las tres, pero el divorcio puede afectar gravemente la convivencia y la productividad de una sociedad. ¿Cuándo hay armonía de ley, moral y cultura? Fundamentalmente cuando hay aprobación moral y cultural hacia el cumplimiento de las obligaciones legales y censura moral y rechazo cultural hacia las actividades ilegales.

¿Cuándo hay divorcio entre ley, moral y cultura? Fundamentalmente cuando hay aprobación moral y cultural a acciones ilegales y cuando hay indiferencia o desaprobación cultural y moral al cumplimiento de obligaciones legales.

Un ejemplo: vía Constitución y ley los ciudadanos nos hemos obligado a colaborar con la justicia y, en particular, a denunciar los delitos; sin embargo, en algunos medios culturales, los criminales han logrado imponer la llamada ley del silencio que se expresa, al menos en Colombia, con la expresión coloquial «no sea sapo». Así se genera informalmente una norma social que contradice y en parte neutraliza la norma legal, con costos enormes para la sociedad.

El poder regulador de la cultura ha sido abordado desde disciplinas como la sociología, la antropología, la psicología social y la economía. Los debates más recientes han acentuado el carácter de permanente cambio e hibridación y el carácter reflexivo de la cultura (hacen parte de la misma los instrumentos de auto-lectura y auto-crítica). Esto favorece los acuerdos y los procesos conscientes de reorientación de la acción y ayuda a comprender las conexiones entre cambio cultural y cambio legal (a veces uno de los dos va adelante y ayuda a impulsar el otro) 


\section{Acción colectiva}

Hay bienes (por lo general públicos, que muchas veces no se pueden obtener privadamente) y que sólo se obtienen si miles o incluso millones de personas cooperan. Hay acción colectiva por ejemplo cuando toda una ciudad o un país ahorran agua.

El llamado problema de la acción colectiva radica en que el óptimo egoísta se da cuando un individuo no coopera pero se beneficia de la cooperación de otros (no ahorra agua pero se beneficia de que los demás ahorraron agua al no sufrir racionamiento; no cumple con la veda a la pesca en una laguna mientras otros vecinos si lo hacen). Para que haya acciones colectivas exitosas se necesita mantener a raya ese comportamiento de gorrón (o recostado, en inglés free-rider).

Y para iniciar una acción colectiva se necesitan altruistas o personas que siguen pautas de conducta simplemente por el hecho de que sería bueno que todos las siguieran. Estos iniciadores, first-movers en la literatura anglosajona, son cooperadores incondicionales que resultan ser claves para llevar la cooperación hasta aquel nivel en que los beneficios cubren los costos y entran a cooperar los cooperadores condicionales (gente que coopera si ya hay un porcentaje suficiente de cooperadores o si ya se ve que la iniciativa va a resultar o si ya va dando resultados tangibles, etc.).

La experiencia nos ha mostrado que resulta muy útil la información sobre el avance de las acciones colectivas (comunicando entre otras el número de cooperadores, el valor de indicadores que miden cuánto nos hemos movido en relación con la meta). Es relevante compartir los argumentos tanto de utilidad como de moralidad. Y también comunicar de manera explícita los caminos que el ciudadano puede decidir seguir (iniciador, cooperador condicional, gorrón) haciendo énfasis en los de mayor cooperación.
Poner los reflectores sobre quienes cooperan y sus razones puede ser una buena alternativa a la costumbre de fijarse primero y sobretodo en quienes no cooperan y sus razones.

La superación concreta de la desconfianza, la capacidad de actuar a partir de hipótesis no pesimistas sobre los demás, ser capaz de suponer en las otras personas altruismo y disposición a cumplir voluntariamente normas, conduce a la derrota de las estrategias asociadas a la desconfianza y al pesimismo sobre el comportamiento del otro («como me va a defraudar, me adelanto a hacerlo yo»)

De hecho «ley, moral y cultura» y «acción colectiva» son enfoques que se relacionan. La existencia de un actor especial central (el estado, el gobierno municipal) se justifica en gran parte por la necesidad de resolver problemas de acción colectiva. Si no hubiera normas legales para obligar a pagar impuestos o para regular el transporte en la ciudad, el oportunismo de algunos tendería a generalizarse y difícilmente se alcanzarían las soluciones óptimas.

\section{Las organizaciones ciudadanas en Colombia como mecanismos de control}

La primera liga de consumidores creada y reconocida en Colombia tuvo su origen en el año 1967 en el Departamento del Tolima. La Fundación de la Confederación Colombiana de Consumidores data del año 1970. Es Federación de Federaciones por estar integrada por organizaciones sindicales, de pensionados, padres de familia, amas de casa, profesionales cívicas y comunitarias y es la organización más representativa de los consumidores colombianos.

El programa de televisión El Boletín del Consumidor, que orienta a los consumidores y usuarios en la protección de sus derechos y en cumplimiento de sus deberes dio su inicio por primera vez en 1970 marcando así un profundo y marcado éxito, popularizando a su personaje Tal Cual. 
En 1981 se expide la Ley 73 por la cual el estado interviene en la distribución de bienes y servicios para la defensa del consumidor Colombiano.

Al año siguiente se expiden los Decretos 1441 y 3466 por los cuales se regula la organización, el reconocimiento y el régimen de control y vigilancia de las ligas y asociaciones de consumidores y se dictan normas relativas a la idoneidad, la calidad, las garantías, las marcas, las leyendas, las propagandas y la fijación pública de precios de bienes y servicios, la responsabilidad de los productores, expendedores y proveedores y todos aquellos actores que intervienen en su cadena de suministros.

La Confederación Colombiana de Consumidores, luego de varios años de trabajo sobre el particular, constituye un frente de integración social de la mayor representatividad nacional, «el pacto por Colombia», el cual fue suscrito conjuntamente con la asociación nacional de usuarios campesinos y la confederación nacional comunal (CNC).

La CCC ha colaborado en la creación de otras organizaciones similares en toda América Latina caracterizada por su marcada eficiencia.

En el año 2000 nace el Sistema Nacional de Consumo "CONGARANTIA», que es un programa que permite a los consumidores y usuarios de bienes y servicios, entablar armónicamente sus relaciones de consumo con los proveedores y les garantiza, dentro de un ambiente de cordialidad y respeto recíproco, la solución rápida, eficaz, oportuna y gratuita de las reclamaciones que llegaren a presentar, sin necesidad de acudir a la justicia ordinaria, involucrando entre otras a la universidad colombiana, por medio de los consultorios jurídicos y practicas universitarias.

El Departamento de Servicios Públicos y Privados, nace en el año 2001 como respuesta a la creciente demanda de peticiones, quejas y re- clamos ante las E.S.P., para la defensa de los derechos de los usuarios y para su participación activa en el desarrollo de tareas de control social.

En el año 2005 se suscribe un convenio internacional con la Asociación de Usuarios de los Servicios Bancarios de España - AUSBANC INTERNACIONAL -, para la protección y defensa de los derechos de los consumidores de servicios bancarios.

En el año 2006, se expide la Ley 1086/2006, por medio de la cual se permite la realización de la Judicatura al servicio de las Ligas y Asociaciones de Consumidores, se abren las puertas para que los estudiantes egresados de las facultades de derecho del país, puedan defender los derechos de los consumidores Colombianos.

\section{Metodología}

Esta investigación tiene como propósito la identificación y medición de las quejas presentadas por los consumidores, referente a la prestación de los servicios públicos en los diferentes sectores de la economía, se realizó en el segundo semestre de 2012, con la Confederación de Consumidores de Colombia, sede Bogotá, investigación de corte cuantitativo, descriptivo, no experimental, con diseño longitudinal, se utilizó la encuesta estructurada como instrumento de recolección de datos, se procesó con el sistema estadístico SPSS, se trabajó con un nivel de confianza de $89 \%$, margen de error de $11 \%$, valores probabilísticos de $p$ y q del $50 \%$ respectivamente por prueba piloto, con una población infinita, lo cual arrojó una muestra de 84 encuestados.

Se consultó a 84 trabajadores expertos de la CCC, quienes amablemente aportaron sus conocimientos e información propia de su quehacer diario, de aquí la alta confiabilidad presentada en los datos obtenidos. Una vez aplicado el instrumento, se procedió a la tabulación, análi- 
sis e interpretación de la información, para determinar la tendencia e incidencia de las quejas de los usuarios de los servicios públicos, su participación y las conclusiones a lugar, frente a la investigación realizada.

\section{Resultados}

A continuación se muestran los resultados obtenidos que se constituyen en referentes para resolver las preguntas de la presente investigación.

\subsection{Pregunta: ¿Cuáles son los sectores eco- nómicos de los cuales más se quejan los consumidores en Colombia?}

La consulta de los expertos arroja el siguiente resultado:

\begin{tabular}{l|c|c}
\multicolumn{1}{c|}{$\begin{array}{c}\text { Sectores } \\
\text { económicos }\end{array}$} & $\begin{array}{c}\mathbf{N}^{\circ} \\
\text { Encuestados }\end{array}$ & $\begin{array}{c}\text { Porcentaje } \\
\text { Válido }\end{array}$ \\
\hline Servicios & 27 & $32 \%$ \\
\hline Comercio & 26 & $31 \%$ \\
\hline Financiero & 5 & $6 \%$ \\
\hline Cárnico & 7 & $8 \%$ \\
\hline $\begin{array}{l}\text { Plazas } \\
\text { de Mercado }\end{array}$ & 16 & $19 \%$ \\
\hline Otras & 3 & $4 \%$ \\
\hline Totales & 84 & $100 \%$ \\
\hline
\end{tabular}

En la tabla de resultados se observa que los sectores en donde más se presentan quejas e inconformidades es en los servicios, en las actividades comerciales y en las plazas de mercados aunque este en un porcentaje menor en relación a los dos sectores anteriores.

Estos resultados llevan a la reflexión que los procesos de prestación de servicios públicos en las entidades creadas para tal fin, presentan falencias internas que están afectando a los ciudadanos y que precisamente son las organizaciones ciudadanas como entes de control, las llamadas a ejercer presión en defensa de los intereses de la comunidad para evidenciar y denunciar dichas inconformidades.

En el mismo sentido, se hace evidente en estos resultados las irregularidades en el sector comercial y las plazas de mercado, es probable que mientras no se apliquen y se hagan cumplir las normas del código del comercio y los procesos establecidos para ello y la comunidad afectada no se manifieste, es difícil para las organizaciones ciudadanas actuar en pro de la defensa de los usuarios y consumidores.

\subsection{Con relación a la pregunta ¿Cuál es la participación porcentual (\%) en los sectores, de las quejan presentadas por los consumi- dores en Colombia?}

Los resultados obtenidos son los siguientes:

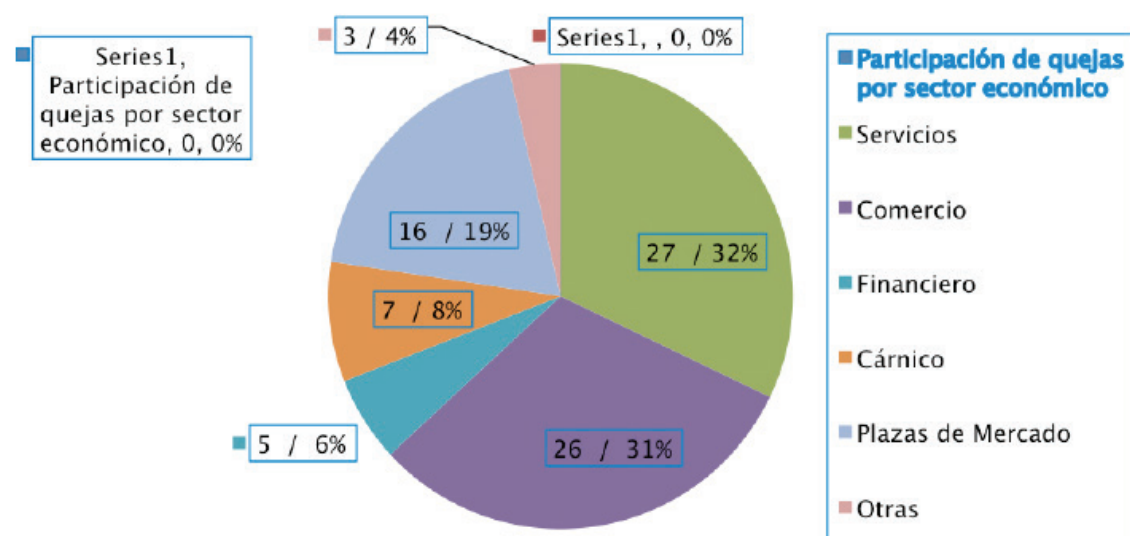




\begin{tabular}{lcc}
\multicolumn{1}{c}{$\begin{array}{c}\text { Servicios } \\
\text { prestados }\end{array}$} & $\begin{array}{c}\mathbf{N}^{\circ} \\
\text { Encuestados }\end{array}$ & $\begin{array}{c}\text { Porcentaje } \\
\text { Válido }\end{array}$ \\
\hline $\begin{array}{l}\text { Servicios } \\
\text { públicos }\end{array}$ & 37 & $44 \%$ \\
$\begin{array}{l}\text { Servicios } \\
\text { en salud }\end{array}$ & 23 & $27 \%$ \\
\hline $\begin{array}{l}\text { Servicios } \\
\text { financieros }\end{array}$ & 16 & $19 \%$ \\
$\begin{array}{l}\text { Servicios } \\
\text { en educación }\end{array}$ & 5 & $6 \%$ \\
\hline $\begin{array}{l}\text { Servicios } \\
\text { en transporte }\end{array}$ & 3 & $4 \%$ \\
\hline Totales & 84 & $100 \%$ \\
\hline
\end{tabular}

El análisis de los resultados presenta un panorama preocupante, la prestación de los servicios públicos arroja el porcentaje más alto, 37 expertos consultados concuerdan que el mayor porcentaje de las quejas y reclamos provienen de irregularidades en la prestación de los servicios públicos, en segundo lugar servicios de salud y en un tercer lugar a los servicios financieros.

Los resultados guardan coherencia con la primera pregunta analizada, el sector servicios en general, es quien presenta mayor porcentaje de inconformidades representadas por quejas y reclamos, seguido el sector salud y luego los servicio financiero. Frente a estos resultados se hace evidente las dificultades y atropellos que se leen diariamente en los medios de comunicación que sufren los usuarios en la prestación de estos servicios. Entonces surgen otros interrogantes como ¿Cuáles son los procesos que se deben surtir para que las organizaciones ciudadanas puedan ejercer un control eficiente?

\section{3 ¿Ciudades, dónde se presentan más quejas por parte de los consumidores?}

Los resultados obtenidos son los siguientes:
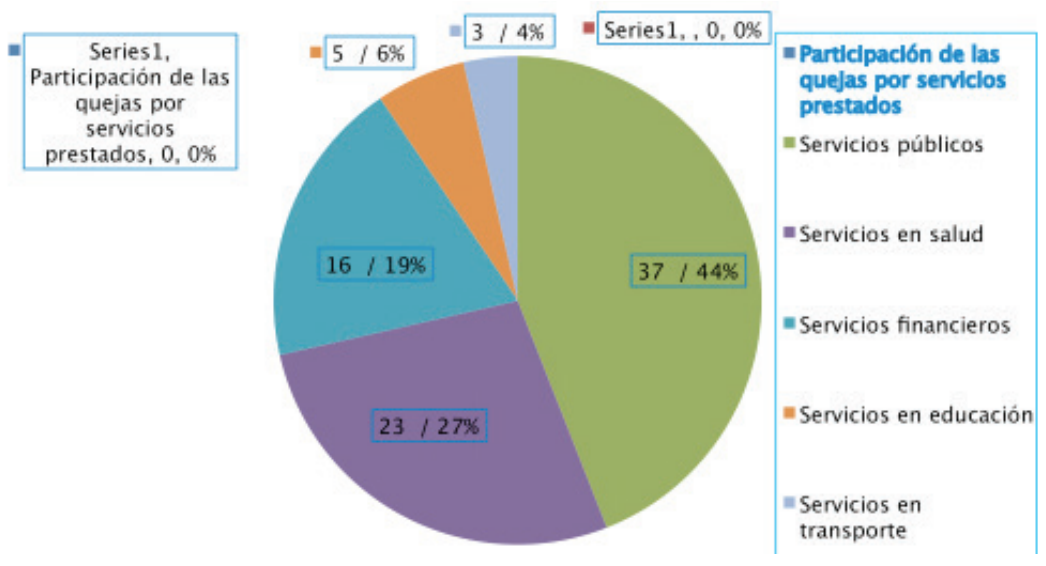

\begin{tabular}{lcc}
$\begin{array}{c}\text { Ciudad de } \\
\text { mayores quejas }\end{array}$ & $\begin{array}{c}\mathbf{N}^{\circ} \\
\text { Encuestados }\end{array}$ & $\begin{array}{c}\text { Porcentaje } \\
\text { válido. }\end{array}$ \\
\hline Bogotá & 31 & $37 \%$ \\
\hline Medellín & 13 & $15 \%$ \\
\hline Cali & 23 & $27 \%$ \\
\hline Bucaramanga & 9 & $11 \%$ \\
\hline Barranquilla & 3 & $4 \%$ \\
\hline Cartagena & 5 & $6 \%$ \\
\hline Totales & $\mathbf{8 4}$ & $\mathbf{1 0 0 \%}$ \\
\hline
\end{tabular}

Los resultados guardan correlación con el número de habitantes por ciudad, Bogotá, es la primera con el porcentaje más alto, seguido Cali, Medellín y Bucaramanga; estas cuatro ciudades suman el $90 \%$ del total de la muestra, reafirmando que son donde se concentra la mayor población y por lo tanto, el núcleo de mayor presentación de quejas. La problemática de la prestación de los servicios con calidad, es una 
constante para todo el país, lo que implica un problema estructural que demanda acciones contundentes frente a las acciones de mejora y sanciones drásticas al prestador que incurra en ello.

\subsection{De las siguientes quejas califique de acuerdo a su participación.}

Los resultados obtenidos son los siguientes:

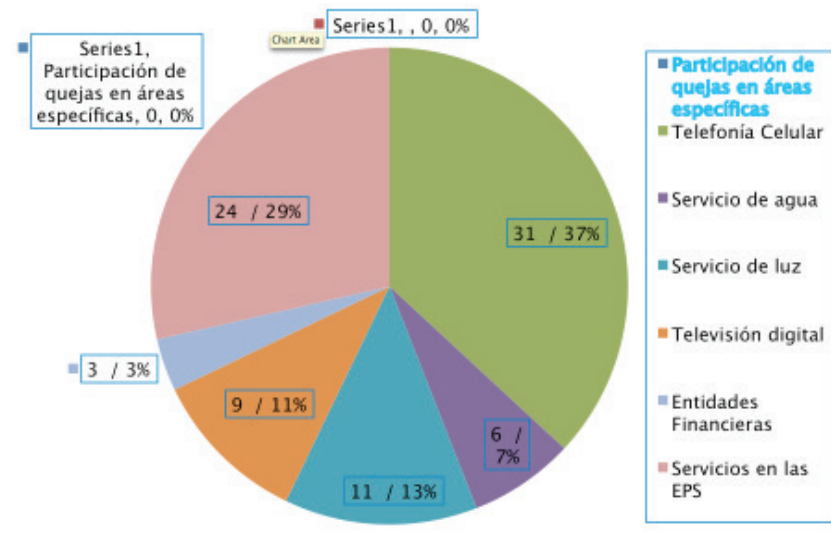

\begin{tabular}{lcc}
\multicolumn{1}{c}{$\begin{array}{c}\text { Área } \\
\text { específica }\end{array}$} & $\begin{array}{c}\mathbf{N}^{\circ} \\
\text { Encuestados }\end{array}$ & $\begin{array}{c}\text { Porcentaje } \\
\text { válido. }\end{array}$ \\
\hline Telefonía Celular & 31 & $37 \%$ \\
\hline Servicio de agua & 6 & $7 \%$ \\
\hline Servicio de luz & 11 & $13 \%$ \\
Televisión digital & 9 & $11 \%$ \\
\hline Entidades & 3 & $4 \%$ \\
Financieras & 24 & $28 \%$ \\
\hline $\begin{array}{l}\text { Servicios en } \\
\text { las EPS }\end{array}$ & & \\
\hline Totales & $\mathbf{8 4}$ & $\mathbf{1 0 0 \%}$ \\
\hline
\end{tabular}

Según los resultados, la queja mas repetitiva es la relacionada con los servicios de telefonía celular, EPS, luz y televisión digital. La telefonía celular y la prestación de servicios de salud en EPS, abanderan las quejas, cifras que encajan con los análisis antes presentados.

Esto refleja la realidad que a diario sentimos como usuarios de estos servicios. El sector financiero es uno de los sectores que generan mayor aceptación en la prestación de servicios por parte de los usuarios.

8.5 ¿Las quejas recibidas se fundamentan en? Los resultados obtenidos son los siguientes:

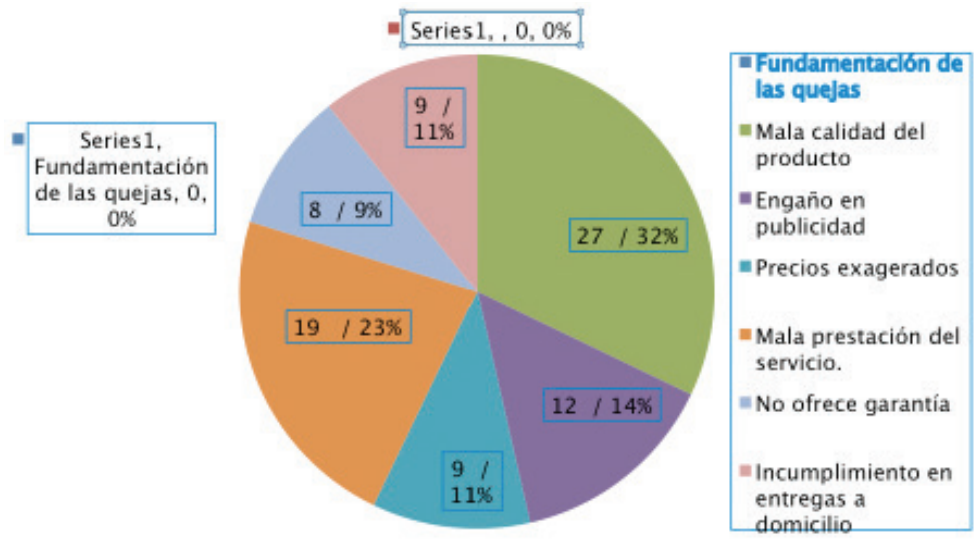




\begin{tabular}{lcc}
$\begin{array}{l}\text { Las quejas se } \\
\text { fundamentan en: }\end{array}$ & $\begin{array}{c}\mathbf{N}^{\circ} \\
\text { Encuestados }\end{array}$ & $\begin{array}{c}\text { Porcentaje } \\
\text { válido. }\end{array}$ \\
\hline $\begin{array}{l}\text { Mala calidad } \\
\text { del producto }\end{array}$ & 27 & $32 \%$ \\
$\begin{array}{l}\text { Engaño en } \\
\text { publicidad }\end{array}$ & 12 & $14 \%$ \\
\hline $\begin{array}{l}\text { Precios } \\
\text { exagerados }\end{array}$ & 9 & $11 \%$ \\
$\begin{array}{l}\text { Mala prestación } \\
\text { del servicio. }\end{array}$ & 19 & $23 \%$ \\
\hline $\begin{array}{l}\text { No ofrece } \\
\text { garantía }\end{array}$ & 8 & $9 \%$ \\
$\begin{array}{l}\text { Incumplimiento } \\
\text { en entregas a } \\
\text { domicilio }\end{array}$ & 9 & $11 \%$ \\
\hline \begin{tabular}{l} 
Totales \\
\hline
\end{tabular} & 84 & $100 \%$ \\
\hline
\end{tabular}

Las quejas que más se recepcionan en la CCCC son por mala calidad del producto, mala prestación del servicio; engaño en la publicidad, precios exagerados y por el incumplimiento en las entregas a domicilio. Lo anterior resume que el $91 \%$ de las quejas se dan por los motivos antes expuestos. El no ofrecimiento de garantía al comprar bienes o productos se da solamente en el $9 \%$ de la muestra encuestada.

EstoS resultados, que siguen siendo coherentes con los anteriores, permiten reflexionar sobre la carencia de valores éticos y de responsabilidad social empresarial en este tipo de organizaciones en Colombia y qué papel esta cumpliendo la CCCC. Este se convierte entonces en un tema importante de reflexión que debe permear a los empresarios de nuestro pais y ser concientes de la importancia de ser éticos y leales con su cliente y más en este momento de globalidad económica en donde una falla de estas, el cliente opta por una nueva empresa u otra marca, para adquirir sus productos o servicios.

\section{6 ¿Quiénes son los que más se quejan?} Los resultados obtenidos son los siguientes:

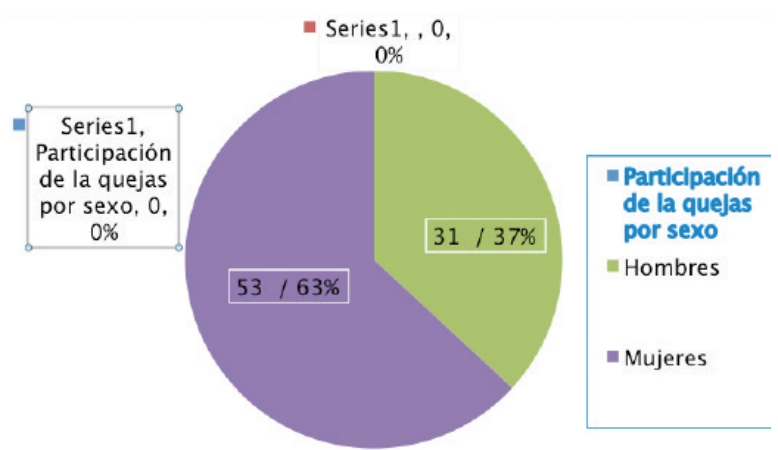

\begin{tabular}{llc}
$\begin{array}{l}\text { Quiénes se } \\
\text { quejan más }\end{array}$ & $\begin{array}{c}\mathbf{N}^{\circ} \\
\text { Encuestados }\end{array}$ & $\begin{array}{c}\text { Porcentaje } \\
\text { válido. }\end{array}$ \\
\hline Hombres & 31 & $37 \%$ \\
Mujeres & 53 & $63 \%$ \\
\hline Totales & $\mathbf{8 4}$ & $\mathbf{1 0 0 \%}$ \\
\hline
\end{tabular}

Referente a la presentación de quejas, los expertos aducen que son las mujeres las que más hacen uso de su derecho con el $63 \%$ de la muestra, manifestando sus quejas e insatisfacciones. Mientras que los expertos aducen que las quejas presentadas por los hombres representan el $37 \%$ de la muestra. Se puede afirmar que realmente el género femenino supera al masculino en un $26 \%$, referente a la presentación de quejas y reclamos, al sentirse atropelladas por las empresas prestadoras de servicios en Colombia.

\section{7 ¿En qué rangos de edad, se presenta el mayor número de las quejas?}

Los resultados obtenidos son los siguientes:

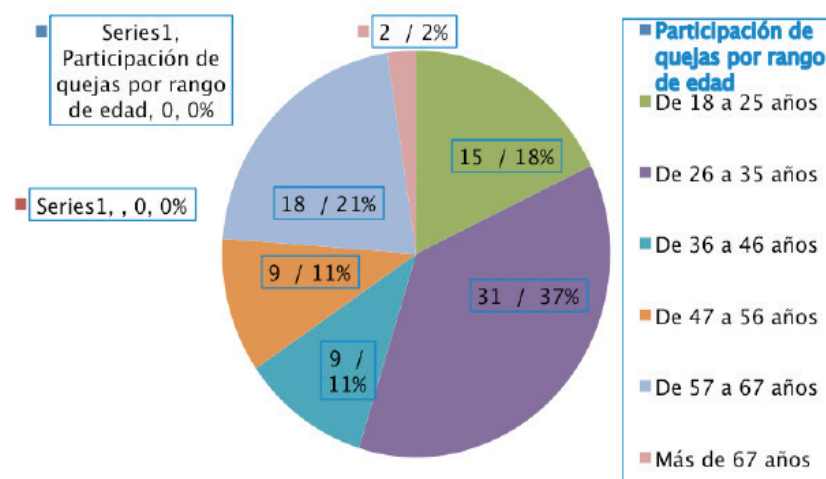




\begin{tabular}{lll}
\multicolumn{1}{c}{$\begin{array}{c}\text { Rangos } \\
\text { de edad }\end{array}$} & $\begin{array}{c}\mathbf{N}^{\circ} \\
\text { Encuestados }\end{array}$ & $\begin{array}{c}\text { Porcentaje } \\
\text { válido. }\end{array}$ \\
\hline De 18 a 25 años & 15 & $18 \%$ \\
\hline De 26 a 35 años & 31 & $37 \%$ \\
\hline De 36 a 46 años & 9 & $11 \%$ \\
\hline De 47 a 56 años & 9 & $11 \%$ \\
\hline De 57 a 67 años & 18 & $21 \%$ \\
\hline Más de 67 años & 2 & $2 \%$ \\
\hline Totales & $\mathbf{8 4}$ & $\mathbf{1 0 0 \%}$ \\
\hline
\end{tabular}

Las personas que mas manifiestan su insatisfacción e inconformidad en Colombia, oscilan entre el rango de edad de 26 a 35 años, opinan 31 expertos, es decir el $37 \%$ de la muestra; seguido por las personas entre 57 a 67 años, donde 18 expertos, es decir el $21 \%$ opinan que esta franja presentan quejas; luego 15 expertos, es decir el $18 \%$ de la muestra afirman que en el rango de edad entre los 1825 años presentan más quejas. En estas tres franjas de edades antes descritas integran el $70 \%$ de las quejas presentadas. El 30\% restante lo conforman las franjas de edad de los 36 a los 56 años y la de más de 67 años.

Muestra esto que la gente joven es exigente hasta los 35 años y luego pasa a marcar nuevamente a la edad de los 57 años para volver a exigir calidad en la prestación de los servicios requeridos.

\section{8 ¿Qué porcentaje de solución se tiene so-} bre el total de quejas recibidas por la CCCC? Los resultados obtenidos son los siguientes:

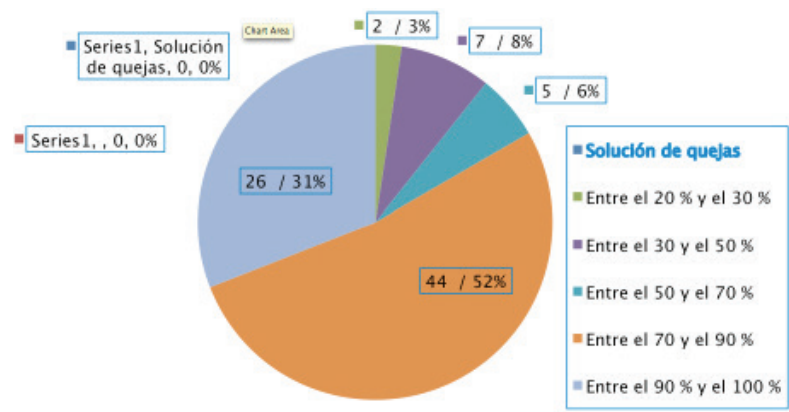

\begin{tabular}{lcc}
$\begin{array}{l}\text { Porcentaje } \\
\text { de solución } \\
\text { de quejas }\end{array}$ & $\begin{array}{c}\mathbf{N}^{\circ} \\
\text { Encuestados }\end{array}$ & $\begin{array}{c}\text { Porcentaje } \\
\text { válido. }\end{array}$ \\
\hline $\begin{array}{l}\text { Entre el 20\% } \\
\text { y el 30\% }\end{array}$ & 2 & $3 \%$ \\
$\begin{array}{l}\text { Entre el 30\% } \\
\text { y el 50\% }\end{array}$ & 7 & $8 \%$ \\
$\begin{array}{l}\text { Entre el 50\% } \\
\text { y el 70\% }\end{array}$ & 5 & $6 \%$ \\
\hline $\begin{array}{l}\text { Entre el 70\% } \\
\text { y el 90\% }\end{array}$ & 44 & $52 \%$ \\
\hline $\begin{array}{l}\text { Entre el 90\% } \\
\text { y el 100\% }\end{array}$ & 26 & $31 \%$ \\
\hline Totales & 84 & $100 \%$ \\
\hline
\end{tabular}

En referencia a la solución de las quejas presentadas, 44 expertos, es decir el $52 \%$ de la muestra, aducen que de cada cien quejas presentadas, se da respuesta entre 70 y 90 de las quejas presentadas, mientras 26 expertos, es decir el $31 \%$ de la muestra dicen que de cada cien quejas presentadas se resuelven entre 90 y 100 de estas quejas. Adicional 14 expertos, es decir el $17 \%$, dicen que de cada cien quejas presentadas se resuelven entre 20 y 69 quejas.

Lo anterior demuestra que el $83 \%$ de los encuestados afirma que de cada cien quejas recibidas se resuelven entre 70 a 100 quejas, demostrando que se ejecuta un proceso importante de respuestas a los quejosos.

\subsection{Desde la óptica de la CCCC, en qué res- ponsabilidad las empresas Colombianas, re- caen con mayor frecuencia.}

Los resultados obtenidos son los siguientes:

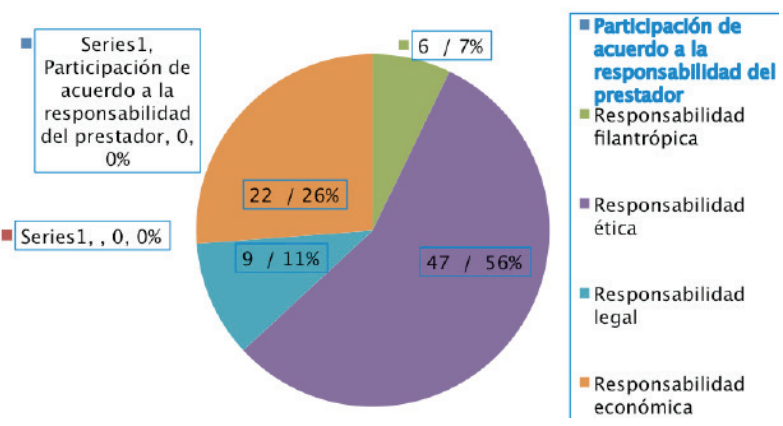




\begin{tabular}{lcc} 
Responsabilidad & $\begin{array}{c}\mathbf{N}^{\circ} \\
\text { Encuestados }\end{array}$ & $\begin{array}{c}\text { Porcentaje } \\
\text { válido }\end{array}$ \\
\hline $\begin{array}{l}\text { Responsabilidad } \\
\text { filantrópica }\end{array}$ & 6 & $7 \%$ \\
$\begin{array}{l}\text { Responsabilidad } \\
\text { ética }\end{array}$ & 47 & $56 \%$ \\
$\begin{array}{l}\text { Responsabilidad } \\
\text { legal }\end{array}$ & 9 & $11 \%$ \\
$\begin{array}{l}\text { Responsabilidad } \\
\text { económica }\end{array}$ & 22 & $26 \%$ \\
\hline Totales & $\mathbf{8 4}$ & $\mathbf{1 0 0 \%}$ \\
\hline
\end{tabular}

De los expertos encuestados, 47 de ellos, es decir el $56 \%$ de la muestra, consideran que la responsabilidad ética es el factor preponderante en cuanto a la responsabilidad empresarial. Mientras que 22 expertos, es decir el $26 \%$ de la muestra dicen que la responsabilidad empresarial es de carácter económico. Luego 15 expertos, es decir el $18 \%$ de la muestra deducen que las responsabilidades son de carácter legal y filantrópico. Se afirma que el $82 \%$ de los encuestados deducen que la responsabilidad empresarial está dada en la parte ética y económica.

Definitivamente la falta de ética de los empresarios en Colombia ocupa el primer puesto en insatisfacción del consumidor y usuario en nuestro país.

\section{Conclusiones}

Es claro que las organizaciones ciudadanas como organismos de control contribuyen a la armonía de ley, la moral y la cultura, aunando esfuerzos al mantenimiento del orden social económico y político, dichas organizaciones, sin duda cumplen un papel fundamental en el equilibrio social, tal como lo fundamenta Douglass North, (1993), pues se han convertido en la forma de representación de muchos grupos sociales, que de manera aislada no han logrado ser oídos en el contexto nacional, es así como éstas y con diferentes formas de expresión, han logrado convertirse en interlocutoras entre el usuario y el Estado Nacional.
Las organizaciones sociales, en algunos casos también son agentes de solución de problemas generados por la sociedad, de ahí que se tenga organizaciones de diversa naturaleza y con diferentes objetivos y metas que dan respuesta a un espectro muy amplio de necesidades o pretensiones de la sociedad civil. Una sociedad donde las organizaciones sociales no existan o no se permitan, será una sociedad donde las redes y relaciones entre sus miembros requieran de solidificarse a fin de tener grupos sociales que generen lazos de solidaridad y de apoyo mutuo, es decir, capital social.

Los resultados obtenidos, luego de realizar el trabajo de campo, dejan ver el espacio que han ganado las organizaciones sociales, concretamente se analiza el caso del espacio ganado por los consumidores a través de la Confederación Colombiana de Consumidores.

Se demuestra con esta investigación, que los consumidores colombianos cada vez son más especializados, conocen la trazabilidad del producto, son conscientes cada vez más conscientes de sus derechos y los exigen ante las empresas productoras y comercializadoras de productos de consumo y/o de servicios. Este comportamiento se refleja con el hecho de que cada día son más el número de consumidores que ponen en conocimiento de la CCC, el atropello que cometen las empresas en Colombia.

Bogotá presenta la de mayor recepción de quejas, el 37\%, Cali $27 \%$, Medellín 15\% cifras proporcionales al tamaño de la población de cada ciudad. Quienes más quejas presentan son las mujeres con un $63 \%$, frente a un $37 \%$ de quejas presentadas por los hombres; es posible que las mujeres en su proceso de emancipación sean quienes más exijan sus derechos. Los resultados también arrojan que quienes más se quejan son las personas en un rango de edad entre 26 a 35 años, el $37 \%$ de la muestra, seguido de las personas mayores en el rango de edad entre 57 y 67 años con el $21 \%$. 
La fundamentación de las quejas se presenta por la mala calidad del producto en un $32 \%$, seguido de inconsistencias en prestación del servicio con un $23 \%$ en oportunidad y pertinencia. El engaño publicitario y la usura en los precios son otros factores objeto de quejas y reclamos, permitiendo en este estudio evidenciar también el grado de responsabilidad de las organizaciones prestadoras de servicios y la ética empresarial con que gestionan la gestión y el desarrollo empresarial en sus organizaciones.

Frente a la oportunidad en la solución de las quejas presentadas, se puede concluir que el $52 \%$ de los encuestados afirma que de cada cien quejas presentadas, se solucionan entre 70 y 90 quejas, mientras que el $31 \%$ de los encuestados dice que se solucionan entre 90 y 100 de las quejas presentadas, reflejando así la eficiencia de la CCC, a pesar de verse diezmada en sus resultados debido a la falta de normatividad existente. Así mismo, estos resultados también reflejan el grado de importancia que para algunos empresarios representan sus clientes en su modelo económico empresarial limitado en el marco de la globalización su horizonte prospectivo, cediendo espacio a otros competidores.

La discusión se da en el contexto del Estado Colombiano, quien carece de capacidad para abordar y solucionar problemáticas sociales como las que se tocan en esta investigación, lo que conlleva a la Sociedad Civil Colombiana a buscar alternativas de asociatividad en la sociedad civil como «escuelas de republicanismo» según Tocqueville, para contribuir a la calidad de la cultura política y las instituciones democráticas para hacer respetar sus derechos inalienables dado que la normatividad es lapsa para aplicas acciones contundentes que impidan la reincidencia y como en el caso de la CCC, los entes de control no cuentan con la infraestructura ni el personal, para atender a cabalidad el volumen de quejas y reclamos que presentan los colombianos.
La información recolectada y presentada en este escrito, puede ser fuente de consulta para otras investigaciones, y una fiel muestra para los empresarios que aún no toman conciencia de los beneficios que puede aportar a la organización el darle importancia a sus clientes y usuarios, mostrando alta calidad en sus productos, eficiente servicio al cliente y eficiencia en los procesos de entrega, sin recurrir a engañosos sistemas publicitarios.

\section{Referencias}

Arias Rivera, M.L. (2004). Ética empresarial e institucional: Apuntes para un debate. Curso del DEADE. La Habana, Cuba.

Confecámaras/FOMIN (2006). Responsabilidad social empresarial. Manual de auto implementación para la empresa. Comprometerse-Confecámaras: Colombia.

Confecámaras/FOMIN (2007). Responsabilidad social empresarial. Manual para la consultoría de responsabilidad social empresarial. Comprometerse-Confecámaras. Colombia.

Churchill JR. Gibert A. (2000). Investigación de Mercados, cuarta edición, México: Thomson Editores.

González Luz Estella.(2011). Organizaciones Ciudadanas y Responsabilidad Social proyectadas a lo global. Modulo, UNAD. Bogotá: Universidad Nacional abierta y a Distancia,

González, E. (1996). Manual sobre participación y organización para la gestión local.

Bogotá: Ediciones Foro Nacional por Colombia.

Gordon, S. (2005). Confianza, capital social y desempeño de organizaciones. Revista Mexicana de Ciencias Políticas y Sociales, vol. XLVII, 193: 41-55.

Ivancevich, J. M. et al. (1997). Gestión, calidad y competitividad. Madrid: McGraw-Hill Interamericana de España, S.A.U. / IRWIN.

Jany, José Nicolás. (2002). Investigación Integral de Mercados, México: Mc. Graw-Hill Editores.

Kliksberg, B. (1999). Capital social y cultura, claves esenciales del desarrollo. Revista de la CEPAL 69: 85-102. 
Kotler, Phillips, 2008. Fundamentos de Mercadeo, México: Pearson Editores.

Mockus, A. (2004) Documento preliminar para la Guía práctica de Cultura Ciudadana. La Cultura Ciudadana como política pública. Ley, Moral y Cultura.

González, F. \& Otero, S. (2006). La presencia diferenciada del Estado, un desafío a los conceptos de gobernabilidad y gobernanza. Consultado en http://www.institutgouvernance.org/fr/analyse/fiche-analyse-237.html

Alcaldía Mayor de Bogotá, Programa Amor por Bogotá. (2010). Cultura ciudadana en Bogotá, nuevas perspectivas. Bogotá, D.C.

Guzmán F. Rodríguez, otros. (2009). Enfoques y nuevos escenarios, Sociedad Civil y Responsabilidad social. Revista. Cultura Ciudadana y Gobierno urbano.

UNFPA. (2007). State of World Population. Informe consultado en http://www.unfpa.org/swp/ 